Original Article

\title{
Medical Student's Skills in Notifying Bad News Based on SPIKES Protocol
}

\author{
Armin Azadi, Mohammadhiwa Abdekhoda, Shafi Habibi
}

\section{ABSTRACT}

OBJECTIVE: This study was carried out to investigate the medical students' skill in notifying bad news based on SPIKES.

METHODOLOGY: The descriptive-analytic studywas conducted in which medical students of Tabriz University of Medical Sciences were participated. To collect data, a two-part questionnaire was used, included 18 questions about how bad news were communicated, and 40 questions based on scenarios of students' skills with bad news communication according to the SPIKES step protocol. Data were analyzed using SPSS software and independent T-test.

RESULTS: The findings showed that students had the most proficiency in the fifth step of the SPIKES (recognizing and expressing sympathy with patient), and the least skill in the $3^{\text {rd }}$ phase of the SPIKES (examining the patient's readiness to receive all or part of the news). A statistical significant difference between skill and performance based on work experiences was observed $(F=3.98, P=0.02)$. However, the data show no significant difference between skill and performance based on characteristic factors i.e. age and gender.

CONCLUSION: According to the SPIKES, students' skills in informing "Bad News" are not at an optimal level. They did not receive the necessary training to notify bad news. Sophisticated students, with more work experience have more skill in informing "Bad News". The training of the "Bad News" informing skills should be on focus to education professionals.

KEYWORDS: Bad news, Medical students, SPIKES protocol, Healthcare

This article may be cited as: Azadi A, Abdekhoda M, Habibi S. Medical Student's Skills in Notifying Bad News Based on SPIKES Protocol. J Liaquat Uni Med Health Sci. 2018;17(04):249-54. doi: 10.22442/jlumhs.181740587

\section{INTRODUCTION}

In medical, "Bad News" means serious and adversarial, warns about the future of patients ${ }^{1}$. For the most healthcare professionals, "Bad News" reporting is very challenging, and this requires training and special skills ${ }^{2}$. Historically, the disclosure of the "Bad News" to patients is not suitable among the physicians ${ }^{3}$.

In previous studies, it was ascertained that patients not only wanted to know information about their own diagnosis, but also they wanted to know about their recovery process. This is one of patient's right to receive information about his or her treatment process, and because of sharing, conveying of bad news is effective in the recovery process. Due to the lack of training and often low experience, doctors are not sure about transferring bad news to patients ${ }^{4}$.

Studies have also revealed that physicians and medical staff are the first and most reliable source of information from the patients ${ }^{5}$. The way the information was provided and conducted by the physician is of paramount importance to patients, and they may not be reluctant to the healing process due to the provided information, so physicians should be aware of the way of providing information and, in other words, they should manage the information. Toutin-Dias G $2018^{6}$ assessed patient and family members' perception concerning bad news communication and compared these with physicians' perceptions. They found that there is a significant difference between physicians and receivers perception of bad news communication. Emotion, invitation and privacy contained the more discrepancies issue.

For transferring "Bad News" several protocols have been developed. SPIKES protocol is the most common one. The SPIKES protocol is an organized way of conveying bad news to patients and their families. It is a stepwise approach to difficult discussions for example when cancer recurs or when treatment options are not responding ${ }^{7}$.This protocol contains six steps: setting, perception, inform, knowledge, empathy, summary and strategy ${ }^{8}$. In term on breaking bad news protocol, Abazari $P$ et $\mathrm{al}^{9}$ in Iran, presented a protocol to breaking bad news for cancer patients, contain six main steps i.e. assessment, planning, preparation, disclosure, support and conclusion. This protocol presented 
based on Iranians religious and cultural viewpoint toward cancer. The researchers hope the presented protocol will be effective guideline to delivering bad news to cancer patients.

Also in this research students' skills in conveying bad news according to the SPIKES protocol in term of gender, age, and job experience have analyzed to answer this question that: how much influences SPIKES protocol get according to the age, gender, and work experience?

\section{METHODOLOGY}

The method of descriptive-analytic study was a survey type. This study was conducted from July to November 2017. The target population was medical students of Tabriz University of Medical Sciences. The criteria for involving in the study was desire to cooperate and participate in the study of medical assistants.

The following formula was is used to determine the sample size in this study. The sampling method is random simple method. In this formula, the variance was estimated by the prototype, which was equal to 0.1 , with $95 \%$ confidence interval and 0.05 error level, determined after calculating the sample size of 152 people.

Formula: $\boldsymbol{n}=\frac{\mathbf{z}^{2} \Sigma^{2}}{\mathbf{d}^{\mathbf{2}}}$

The data gathering tools werebased on previous studies. The Validity of the questionnaire was assessed using the Content Validity Rate and Content Validity Ratio (CVR) criteria and in accordance with an expert judgment. To assess the reliability of the questionnaire, Cronbach's alpha test was utilized to examine the correlation of the questionnaire which was $\alpha=0.9$.

The questionnaire consisted of 18 questions about how to convey "Bad News" and 40 other questions depending on the students' skills of transferring bad news methods based on 6-staged Spikes protocol. For each question there were five choices: Always, Often, Sometimes, Seldom and Never. Questionnaire analysis was performed in accordance with 5 Likert scale scores in a manner that was assigned to the options of always, often, sometimes, seldom, and never scores $5,4,3,2$, and 1 , respectively.

After entering data into the computer, it was analyzed statistically. Analyzing was performed by SPSS, statistic software. Students' knowledge of the way of notifying bad news was analyzed by questionnaire questions and with respect to frequency, median and average amount. To analyze the significant differences in students' skills according to age, gender, and performance, Independent-T-test and ANOVA were used.

\section{RESULTS}

Demographic information of the sample presented in Table I. The results show that from 152 participants in this research, there were 82 male $(53.9 \%)$ and 70 female (46.1\%). The mean age of Assistant Students of Tabriz University of Medical Sciences was 34/30 years and the average work record was 3.7 , also there were 62 single $(40.8 \%)$ and 66 married $(43.4 \%)$ participants. (See Table I).

Outcomes of this research indicated that $51.3 \%$ participants in an average less than 5 times gave their patients bad news. Other findings showed that $57.9 \%$ of assistant students were somewhat reluctant to report bad news. $62.5 \%$ somewhat less likely to trust their abilities and skills in giving bad news. $92.8 \%$ of the students believed that bad news needed special skills.

Findings of this research also exhibited that $39.5 \%$ of participants sometimes had a pre-designed strategy to inform bad news. $52 \%$ of the participants did not have enough skills to deal with the patient's feelings of giving bad news. $54.5 \%$ of Assistants did not have any strategy to convey bad news. Most people in this study $(92.8 \%)$ believed that existing strategy or approach in their job would be useful. Less than half of the participants $(32.2 \%)$ found out coping with patients' feelings the most difficult part. Around $27 \%$ of people who were familiar with SPIKES protocol, found setting interview situation easier, and $17.1 \%$ of students believed that telling the news to patients is the most difficult part of SPIKES protocol.

Table II presented the students' skill level in notifying bad news according to the SPIKES protocol. The results show that the most predominant skill of the students is related to the emotional perception and sympathy (empathy) with an average amount of 4.37 and the least skill identified with the section that examines the patient's readiness to receive the whole or part of the newsletter (invitation) with an average amount of 4.01. A significant difference between skill level and gender-based performance showed that there was no significant difference between skill and gender-based performance (See Table III). This means that gender does not affect students in transferring the "Bad News" according to the SPIKES protocol ( $\mathrm{P}=0.57, \mathrm{~T}=0.561)$.

Considering the significant difference between skill level and performance based on age, there was no significant difference between students' skills and performance in reporting bad news according to age-based SPIKES protocol (See Table II). This means that age is also not important in transferring bad news among students $(P=0.5, F=1.6)$.

Considering the significant difference between students' skills and performance in informing bad 
news, based on their work experience there was a momentous difference between the performance of the participants in the study in accordance with their work experience $(P=0.2, \quad F=3.98)$, that means, students who have higher work experience have more skills in giving bad news according to the SPIKES protocol, and work experience has a decisive role in informing bad news (See Table III).

TABLE I:

DEMOGRAPHIC INFORMATION OF THE SAMPLE

\begin{tabular}{|c|c|c|c|c|c|}
\hline Demographics & Category & Freq. & Per. & SD & Mean \\
\hline \multirow{4}{*}{ Gender } & Male & 82 & $53 / 9$ & & \\
\hline & Female & 70 & $46 / 1$ & & \\
\hline & Missing & - & - & & \\
\hline & Total & 152 & 100 & & \\
\hline \multirow{6}{*}{ Age } & $26-30$ & 88 & $57 / 9$ & \multirow{6}{*}{$30 / 34$} & \multirow{6}{*}{$3 / 21$} \\
\hline & $31-35$ & 55 & $36 / 2$ & & \\
\hline & $36-40$ & 4 & $2 / 6$ & & \\
\hline & $40<$ & 2 & $1 / 3$ & & \\
\hline & Missing & 3 & 2.0 & & \\
\hline & Total & 149 & 98.0 & & \\
\hline \multirow{7}{*}{$\begin{array}{l}\text { Work } \\
\text { experience }\end{array}$} & $1-5$ & 86 & $56 / 6$ & \multirow{7}{*}{3.70} & \multirow{7}{*}{$3 / 24$} \\
\hline & $6-10$ & 8 & $5 / 3$ & & \\
\hline & $11-15$ & 2 & $1 / 3$ & & \\
\hline & $16-20$ & 3 & 2.0 & & \\
\hline & $20<$ & 2 & $1 / 3$ & & \\
\hline & Missing & 51 & 33.6 & & \\
\hline & Total & 101 & $66 / 4$ & & \\
\hline
\end{tabular}

TABLE II: STUDENT'S SKILL LEVEL IN NOTIFYING BAD NEWS BASED ON SPIKES

\begin{tabular}{|l|c|}
\hline SPKIES Protocol component & Average rate \\
\hline Setting & 4.26 \\
\hline Perception & 4.23 \\
\hline Invitation & 4.01 \\
\hline Knowledge & 4.31 \\
\hline Empathy & 4.37 \\
\hline Strategy & 4.04 \\
\hline
\end{tabular}

\section{DISCUSSION}

According to our study, most of the individuals $(53.9 \%)$ did not have a specific training in informing
TABLE III: SIGNIFICANT DIFFERENCES BETWEEN STUDENTS' SKILLS AND PERFORMANCE IN TRANSFERRING "BAD NEWS" BASED ON GENDER (MALE OR FEMALE), AGE AND WORK EXPERIENCE

\begin{tabular}{|l|c|c|c|}
\hline \multicolumn{1}{|c|}{ Category } & F & T & P-value \\
\hline Gender & - & $0 / 561$ & $0 / 57$ \\
\hline Age & $1 / 6$ & - & $0 / 9$ \\
\hline Work experience & $3 / 98$ & - & $0 / 02$ \\
\hline
\end{tabular}

bad news. A research in Kerman University of Medical Sciences demonstrated that less than half of all patients, report themselves to cancer support groups, which can be due to the lack of proper training, the absence of known active supportive centers and even lack of the attention to psychological support from physicians $^{10}$.

Based on the findings of the present study, more than 50 percent of the participants were slightly trusted in their ability to make bad news and had a low tendency to report bad news. The proper training of the bad news transmission modalities is to reduce the dissatisfaction and insecurity that was provided by physicians in informing bad news ${ }^{10}$. The results of a study in the Buknell Hospital on how to report bad news to patients showed that all physicians were dissatisfied with the fact that they had to send bad news to the patient, and their main reason was their complaint of not knowing how to transmit bad news, in order to minimize the unfavorable influences on the patient ${ }^{11}$. The findings of participants communication skills exhibited that many subjects of the study did not have enough confidence in transfering bad news ${ }^{3}$. Fujimori M 2017 ${ }^{12}$ acknowledged that patient background affected their preferences in communication of bad news. They also remarked that patients characteristics should be considered by physicians in delivering bad news and healthcare staff should chose a suitable communication style to inform bad news.

The outcomes of the present study showed that the participants did not have a specific approach to give bad news, and most believed that the existence of an approach and strategy to give bad news was useful and required special skills in transfering bad news. A study by Garg A $1997^{13}$ which its results were published in the Journal of the Association of Doctors of Canada, indicated that $82 \%$ of the students believed that the course to inform the bad news would be effectiveand necessary. In addition, in a study established at the University of George Washington School Of Pedagogy, training courses provided to assistants on bad news, caused significant 
improvement on their ability to inform and connect with parents of patients in an unpleasant diagnosis ${ }^{14}$ Abdekhoda M $2016^{15}$ reported that the training intervention provides considerable opportunity to improve medical student's information literacy skills. Gorniewicz J $2017^{16}$ also found that the brief breaking bad news (BBN) training model is a significant method to improving medical student's skills in delivering bad news. Unexpectedly, Setubal MSV $2018^{17}$ reported that "The SPIKES training did not significantly impact the residents' performance".

In the present study, most people considered confronting the patient's emotions as the most difficult part and mentioned reporting the recurrence of disease is the hardest thing. Results show that, responding to the patient's emotion is one of the more difficult and an essential part of a one news report ${ }^{18}$.

In this study, most participants tried to get support from relatives of the patient in transferring news (first phase of Spikes: setting the interview conditions). The results of the study by Baile WF $2000^{3}$ exhibited that in reporting bad news, most patients desire someone else to be incorporated with them, it is necessary to be involved with the patient and leave this choice to the patient.

In this research, most people tended to give their patients face-to-face news and refused to give it on telephone (Spikes I phase: setting interview conditions). The results of previous studies have shown that for reporting bad news, it would be helpful to provide a room for interview, but if not available, the Parabon around the patient can be used ${ }^{3}$.

Students believed that they should inform their patients in a plain and fluent language and they must avoid using specialized words and phrases (the fourth phase of Spikes: providing news to the patient). The results of the study by Baile WF $2000^{3}$ demonstrated that patients should be informed at the level of their understanding, avoid saying special words.

In this study, there was no significant difference between students' skills and performance in informing bad news according to gender (See Table II). In other words, gender is not an effective object according to SPIKES protocol $(P=0.57, T=0.561)$. However, in a study by Locatelli $C 2013^{19}$, which is according to the beliefs and practices of the 50 Italian oncologists, bad news skills depended not only on the patient's age, but also on the age and gender of physicians. The results of Stiefel F $2013^{20}$ study on the skills and training requirementsof medical students showed that the sex is an effective factor. The results of this study also indicated that female students do most of the patient-centered interviews, because they provide more health information in the treatment scenario and reassure the patient in terms of pain relief, while male students focus more on the psychological and patient experiences in the treatment scenario.

In the present study, a significant difference between skill and performance based on age did not show any significant difference between skill and performance with age $(F=1.6, P=0.5)$. Another study results revealed that respondents aged over 50 were significantly more likely to support their patients' psychologically ${ }^{21}$. In another study conducted in Kerman University of Medical Sciences, according to the results, no significant relationship was found between age and psychological support score ${ }^{10}$.

A significant difference between skill and performance based on work experience showed that there was a significant difference between the performance of the participants in the study based on the work experience $(P=0.02, F=3.98)$. Therefore, students with more work experience can be said to have more skill in giving bad news according to the SPIKES protocol, and work experience plays a crucial role in informing bad news. The results of the study by Locatelli $C$ $2013^{19}$ revealed that doctors who had less work experience than other doctors were in more difficult conditions because of their lack of experience in giving bad news to the patient's family, especially the elderly ones. The results of studies by Eggly $S 2011^{22}$ and Kallergis G $2009^{23}$ also showed that health professionals, with enough knowledge and the high work experience, were good people for transferring the "Bad News".

\section{CONCLUSION}

Reporting "Bad News" is a skill and it's learning needs a systemic and university-based teachings. The results of the study showed that most autistic students did not receive specific training on how to report bad news based on the SPIKES protocol, and believe that giving bad news to patients requires a special approach and skill.

Therefore, it is imperative that undergraduate students get acquainted with the bad news science methods that they face in their professional life and learn the training and skills they need. It is proposed that bad news information should be included in the student's educational curriculum to provide practical and academic skills in this regard.

According to the results obtained in this study, the age and sex of Assistants students have no significant effect on reporting bad news to patients, but the results demonstrated that work experience is an important factor in students' skills in bad news reporting in accordance with the SPIKES protocol, this means that students with more work experience have more skills in informing patients about "bad news". Therefore, it can be concluded that informing bad 
news, if it is feasible, should be left to the medical staff with more work experience.

\section{Conflicts of Interests}

The authors declare there are no competing interests.

\section{Ethics statement}

Different ethical aspects of present research was approved by the Ethics Council of Tabriz University of Medical Sciences (IR.TBZMED.REC.1395.51325 )and all the participants signed the consent form of the research.

\section{Source of Support}

Tabriz University of Medical Sciences (Grant NO\# 56753)

\section{ACKNOWLEDGMENT}

This study was supported by Tabriz University of Medical Sciences (Grant NO\# 56753).

\section{REFRENCES}

1. Seifart C, Hofmann M, Bar T, Riera Knorrenschild $J$, Saifart U, Rief W. Breaking bad news-what patients want and what they get: evaluating the SPIKES protocol in Germany. Ann Oncol 2014; 25 (3): 707-11. doi: 10.1093/annonc/mdt582.

2. Dixon L, Gavani D. Patients' Perceptions of Receiving a Diagnosis of a Hematological Malignancy, Following the SPIKES Protocol. Int J Med Health Biomed BioEng Pharmaceut Eng 2015; 9(9): 703-07.

3. Baile WF, Buckman R, Lenzi R, Glober G, Beale EA, Kudelka AP. SPIKES-A Six-Step Protocol For Delivering Bad News: Application to the Patient with Cancer. Oncologist 2000; 5(4): 302-11.

4. Narayanan V, Bista B, Koshy C. 'BREAKS' protocol for breaking bad news. Indian J Palliat Care 2010; 16(2):61-65.

5. Perumal SS, Prasad S, Surapaneni KM, Joshsi A. Health information-seeking behavior among hypothyroid patients at Saveetha Medical College and Hospital. Ethiop J Health Sci 2015; 25(2): 147-54.

6. Toutin-Dias G, Daglius-Dias R, Scalabrini-Neto A. Breaking bad news in the emergency department: a comparative analysis among residents, patients and family members' perceptions. Eur J Emerg Med 2018; 25(1):71-76. doi: 10.1097/MEJ. 0000000000000404.

7. Kaplan M. SPIKES: A framework for breaking bad news to patients with Cancer. Clin J Oncol Nurs 2010; 14(4):514-6. doi: 10.1188/10.CJON. 514-516.

8. Park I, Gupta A, Mandani K, Haubner L, Peckler
B. Breaking bad news education for emergency medicine residents: A novel training module using simulation with the SPIKES protocol. J Emerg Trauma Shock 2010; 3(4):385-88.

9. Abazari $P$, Taleghani $F$, Hematti $S$, Malekian A, Mokarian F, Hakimian SM, et al. Breaking bad news protocol for cancer disclosure: an Iranian version. J Med Ethics Hist Med 2017; 10: 1-7.

10. Ghafari Nezhad AR, Salari P, Mitrzazadeh A. How to inform bad news patients among physicians of Kerman University of Medical Sciences. Medical journal of Hormozgan University. 2006; 10(2): 179 $-184$

11. Ptacek J, Fries EA, Eberhardt TL, Ptacek JJ. Breaking bad news to patients: physicians' perceptions of the process. Support Care Cancer 1999; 7(3):113-20.

12. Fujimori $M$, Akechi $T$, Uchitomi $Y$. Factors associated with patient preferences for communication of bad news. Palliat Support Care 2017;15 (3):328-35. doi: 10.1017/S147895151600078X.

13. Garg A, Buckman R, Kason Y. Teaching medical students how to break bad news. CMAJ 1997; 156(8):1159-64.

14. Harrahill M. Giving bad news gracefully. J Emerg Nurs 2005; 31(3):312-14.

15. Abdekhoda M, Dehnad A, Yousefi M. Effectiveness of training intervention to improve medical student's information literacy skills. Korean J Med Educ 2016; 28(4):391-95.

16. Gorniewicz J, Floyd M, Krishnan K, Bishop TW, Tudiver F, Lang F. Breaking bad news to patients with cancer: A randomized control trial of a brief communication skills training module incorporating the stories and preferences of actual patients. Patient Educ Couns 2017; 100(4):655-66.

17. Setubal MSV, Antonio MÂRGM, Amaral EM, Boult J. Improving Perinatology Residents' Skills in Breaking Bad News: A Randomized Intervention Study. Rev Bras Ginecol Obstet 2018; 40(3): $137-$ 146. doi: $10.1055 / \mathrm{s}-0037-1621741$.

18. Newton JT, Fiske J. Breaking bad news: a guide for dental healthcare professionals. British Dental J 1999; 186(6):278-81.

19. Locatelli C, Piselli P, Cicerchia M, Repetto L. Physicians' age and sex influence breaking bad news to elderly cancer patients. Beliefs and practices of 50 Italian oncologists: the G.I.O.Ger study. Psychooncology 2013; 22(5):1112-19. doi: 10.1002/pon.3110.

20. Stiefel F, Bourquin C, Layat C, Vadot S, Bonvin R, Berney A. Medical students' skills and needs for training in breaking bad news. J Cancer Educ 2013; 28(1):187-91. 
21. Dosanjh S, Barnes J, Bhandari M. Barriers to breaking bad news among medical and surgical residents. Med Educ 2001; 35(3):197-205.

22. Eggly S, Harper FW, Penner LA, Gleason MJ, Foster T, Albrecht T. Variation in question asking during cancer clinical interactions: a potential source of disparities in access to information. Patient Educ Couns 2011; 82(1):63-68.

23. Kallergis G. Informing the cancer patient and family. J BUON 2009; 14(1):109-14.

\section{AUTHOR AFFILIATION:}

Armin Azadi

MSc Student of Medical library and Information Sciences

School of Health Management and Medical Informatics

Tabriz University of medical sciences, Tabriz, Iran.

Mohammadhiwa Abdekhoda (Corresponding Author) Assistance Professor in Health Information Management Iranian Center of Excellence in Health Management (IceHM) School of Management and Medical Informatics Tabriz University of Medical Sciences, Tabriz, Iran. Email: hiwaabdekhoda@gmail.com

\section{Shafi Habibi}

Assistance Professor in Health Information Management Department of Medical Library and Information Sciences School of Health Management and Medical Informatics Tabriz University of medical sciences, Tabriz, Iran. 